\section{Mesa radicante: experiencia e imagen}

Trixi Allina Bloch * y Alejandro

Jaramillo Hoyos ${ }^{* *}$

Resumen: Se relatará acerca del proyecto Mesa radicante que fue una experiencia enmarcada dentro del proceso del proyecto Huerta que mediante diversas estrategias estimula la emergencia de narrativas del territorio buscando hacer visible en la imagen la situación, el lugar y las acciones, y establecer un vínculo entre lo rural y lo urbano.

Palabras clave: proceso - estrategias - narrativas - imagen - rural - urbano.

[Resúmenes en inglés y portugués en la página 133]

${ }^{*}$ ) Trixi Allina Bloch: artista y antropóloga, artista independiente con una larga trayectoria académica en la Universidad Nacional de Colombia; desde el ejercicio sobre lo fotográfico y sobre la imagen desarrolla desde hace varios años procesos en arte colaborativo.

${ }^{* *}$ Alejandro Jaramillo Hoyos: artista audiovisual y escénico. Experiencia en televisión pública. Docente e investigador en la Facultad de Bellas Artes de la Universidad Pedagógica Nacional.

Ritmos

¿qué se espera?

¿qué se debe esperar?

Sorpresas, marcas

¿de qué manera se construyen?

El espacio se comunica, nos comunica, nos habla, se deja ver, se dispone, se despliega y configura.

(Paisaje leído) ${ }^{1}$

Mesa radicante es una experiencia enmarcada dentro del proceso del proyecto Huerta que mediante diversas estrategias estimula la emergencia de narrativas del territorio buscando hacer visible en la imagen la situación, el lugar y las acciones, y establecer un vínculo entre lo rural y lo urbano.

Desde el año 2014 la huerta se instala en proceso mediante el formato colaborativo, constituyéndose en una plataforma de exploración estética en el ámbito de las relaciones entre 
arte y vida con énfasis en las redes de circulación, intercambio y reciprocidad de la cotidianeidad rural.

El objetivo central del proyecto, poniendo la práctica artística relacional y colaborativa al servicio de la producción de imágenes, consistió en instalar una experiencia colectiva sobre las huertas y el mercado, y más allá de la discursividad sobre la vida cotidiana y la producción y circulación de alimentos en su entorno, se propuso captar mediante diversas materialidades de la imagen, las cualidades de su contexto e interacciones para devolver a las comunidades -actores del proyecto- un ejercicio performativo de exposición de arte in situ.

\section{La huerta como producción de conocimiento}

El proceso como laboratorio creativo y de investigación, ha permitido establecer una rutina de estudio sobre los diferentes procedimientos, herramientas mediales y relaciones conceptuales entre la práctica artística, la circulación, el conocimiento y la interacción en comunidades rurales.

Más allá de activar un diálogo entre asistentes, dada la performatividad de los encuentros a los que la mesa de la huerta convoca, registramos, documentamos y revelamos con la imagen las relaciones entre ellos y el paisaje como una manifestación sensible del pensamiento y las maneras de ser. Estas experiencias nos han permitido decantar preguntas y correlacionar dudas e intuiciones. Hoy, de manera retrospectiva, podemos decir que más allá de los diálogos, del intercambio y la circulación de saberes y semillas que produce la huerta, de la performatividad emerge una esfera gestual en las imágenes que nos remite a la relación estética atendiendo a las manifestaciones de la sensibilidad y el gusto entre humanos y de ellos con el entorno (Agamben, 2016, p. 10).

La intersección entre diversas esferas de la experiencia sensible, el gusto, el conocimiento y la expresividad, va dando paso a que estos proyectos de arte introduzcan y configuren un archivo sobre una indagación visual y sonora de las interacciones entre la vida rural y urbana en consideración a los vínculos entre campesinos, sus prácticas de reproducción cultural y sus referentes patrimoniales en la vida contemporánea.

En el año 2016, de la mano de la Fundación Erigaie el proyecto Mesa radicante recibió el apoyo del 'Programa Nacional de Concertación Cultural del Ministerio de Cultura de Colombia' ${ }^{2}$ para poner a rodar el espacio de encuentro mediante los dispositivos de la mesa y el carro recorriendo carreteras veredales y conectando huertas con las plazas de mercado. El procedimiento consistió en poner la práctica artística al servicio de la generación de imágenes y buscar una imagen de $\mathbf{s i}^{3}$ haciendo reconocimiento a la gestualidad, activando el diálogo entre cuerpo y paisaje; entre prácticas de siembra y circulación; entre producción, intercambio y comercio. Esta relación entre forma y trayecto mediante el carro y en torno al encuentro, perfiló un foco en el gesto de los actores y de las huertas como manifestación visible de potencias invisibles (Agamben, 2007, p. 319) en la vida rural. Afirma Giorgio Agamben:

Debemos ahora medir todas las consecuencias de esta figura de la potencia que, donándose a sí misma, se salva y acrecienta en el acto. Ella nos obliga a re- 
pensar desde el inicio no sólo la relación entre potencia y acto, entre lo posible y lo real, sino también a considerar de manera nueva, en la estética, el estatuto del acto de la creación y de la obra y, en política, el problema de la conservación del poder constituyente en el poder constituido (Agamben, 2007, p. 367).

La mirada instalada en este laboratorio se guió en consideración del acto de creación y colaboración como una nueva relación entre la acción y la potencia del lenguaje gestual; de esta manera, la posibilidad creativa y colectiva se mantiene y se aviva en las imágenes producidas, se manifiesta en el acto creativo y en las intervenciones que instaura en las imágenes una re-creación de los sujetos y de los paisajes habitados por ellos.

Al decir de esta 'dimensión estética de las imágenes', una Imagen de sí refiere al gesto que emerge y cuestiona la certidumbre de la identidad otorgada desde el exterior; en ella habita no sólo el tiempo singular del cuerpo plantado de quien posa o de quien observa. En la fotografía se capta la experiencia sesgada por el tiempo, se escribe en las capas de signos que nos pertenecen a todos: las del objeto, las de los sujetos y las del territorio. Así la fotografía, además de captar los instantes nos lleva de la mano a preguntarnos sobre el gesto como el más diciente rasgo de sentido no actuado, como un acto súbito, instantáneo, que subsana la imposibilidad de hablar o que refiere a una realidad ya no presente, como dijo Benjamin en 1931, la fotografía nos instala en ese "minuto visible pero ya lejano, donde el futuro anida de manera tan elocuente que, mirando hacia atrás, podremos descubrirlo" (Benjamin, 2011, p. 17) en cada 'objeto' fotografiado; nos vincula al pasado y dando sentido al futuro se constituye en un vínculo con la tierra.

Esta voluntad por activar la imagen de sí, es la que desplaza el foco de lo fotográfico y pone en jaque la nitidez hipertécnica de los dispositivos que 'mienten' embelleciendo lo bello. Así, en busca de desplazar la identidad hacia una lectura colectiva -en grupo/solitario-, la performatividad que subyace al encuentro, moviliza el orden del discurso organizado y, transforma la forma del mundo establecida, llama a otros devenires inscritos en las capas de sentido de la foto para que habiten la imagen, que es conocimiento.

Producir un conocimiento se arraiga en una doble articulación de la imagen: la singularidad y la simultaneidad como un acto de interacción colectiva. Dado que la imagen nos refiere a la más exquisita práctica del lenguaje y a la doble articulación del sentido que se instala al 'leer y escribir' en colaboración, rompiendo esquemas y modelos de presupuestos sobre la investigación; estas acciones promueven la integración de saberes no instituidos y la circulación en circuitos de borde.

\section{Proceso-reflexión}

Los encuentros e interacciones, reflejaron aspectos actuales de la vida cotidiana campesina y sus determinantes culturales asociadas a las transformaciones económicas. Mediante aparatos de registro se captaron resonancias y singularidades del cuerpo, la huerta y el mercado, con los cuales producir series que conectaran las potencias del camino, el poblado y el mercado. 
La exploración tomó como directriz las formas de circulación y movilidad que hoy permiten a los campesinos de los municipios de Tinjacá, Ráquira y Sutamarchán ${ }^{4}$ interactuar, dado que hoy se opera una gran transformación 'administrativa' en las plazas de mercado. Éstas desde la Colonia fueron instituidas no sólo como lugares para el intercambio de productos sino como modos de encuentro que sostuvieran las redes solidarias comunales; de esta manera, intercambio y encuentro se ligaron como actividad a la vida doméstica y hortelana/agrícola.

Se desarrolló un proceso que dando lugar a una imagen de sí, retornaría a la comunidad y a sus actores. Se hizo seguimiento a las dinámicas de articulación con la huerta como núcleo cultural de la vida doméstica; alrededor de los alimentos, el salón comunal, las rutas y el transporte, y la plaza de mercado, se manifestaron como escenarios políticos del encuentro y las transacciones sociales, simbólicas y económicas.

La conexión entre nodos del territorio, integrados al horizonte del paisaje, dibujó un perfil, mostrando sus texturas y visibilizando experiencias a los propios actores que los viven y los actualizan día a día inscribiendo sus marcas, huellas y presencias como labriegos. Nos referimos al aquí y ahora y sin embargo encontramos que, al no abordar explícitamente un pasado narrado, fueron las fricciones mostradas durante los encuentros y los comentarios los que, manifestando el presente, llevaron a los participantes a plantear preguntas y reflexiones sobre su paisaje y su destino.

Entendimos que un proceso de reflexividad animó la mirada sobre sí pues introdujo en el lenguaje el acto de suscitar 'comentarios' enlazados al repertorio de significados y sentidos propios del lugar.

"La imagen no sólo presenta algo sino que quien mira hace un movimiento de co-presentación del mismo gesto de presentar", Según Menke, citado por Romina Conti (Conti, 2014, p. 10).

Los medios locales, entre ellos el 'voz a voz', la comunicación telefónica, las visitas, los impresos como recordatorios de los encuentros también fueron sustanciales para las dinámicas de interacción de estos procesos. Sin embargo, más que confirmar hechos se manifestaron incertidumbres al incluir 'temas difíciles' que no se verbalizan en su cotidianidad habitual.

Registramos que, desplazados los animales como medios de transporte y trabajo, el camión repartidor hoy se instala como mercado o 'servicio a domicilio' -como lo llaman ellos-, afirmando que viven una cierta 'mímesis' con los procesos urbanos; el camión hace las veces de mediador trashumante entre veredas y municipios a la vez que des-plaza la producción y las mercancías, re-localiza los encuentros y los intercambios entre actores de una vereda y otra, de un municipio a otro. En el año 2016, dentro de las observaciones preliminares del proyecto, hicimos una visita a 'la Plaza de las Sepulturas' vereda Ermitaño-Sutamarchán, lugar del que habíamos sido informados que funcionaba un mercado veredal. En esa ocasión al llegar al lugar, encontramos un espacio dispuesto como plaza de mercado tradicional pero notamos la ausencia de puestos de mercado. En su lugar, varios camiones de transporte de alimentos estaban parqueados de manera que la gente podía acercarse y comprar en el camión verduras y otros.

Había un vendedor de ganado en pie que quería vender un buey y un grupo de personas se reunía para dialogar mientras bebían una cerveza frente a una caseta de latón que funcionaba como tienda ${ }^{5}$. 
Al regresar, durante la acción Radicante, en 2017, sólo encontramos las huellas de la vida del mercado que habíamos conocido el año anterior; ahora, el lugar seguía siendo utilizado para compra y venta de alimentos pero sólo desde uno o dos camiones que vendían a menos de diez personas que se acercaban a comprar. La tienda de cerveza, cerrada y las personas muy renuentes a relacionarse con 'esos extraños' que llegábamos a interactuar en este espacio que había dejado de ser de 'encuentro'.

Lo actual en la vereda Ermitaño del municipio de Sutamarchán es que el camión-plaza borre fronteras, participe y represente la emergencia visible de un tejido-red de la cultura transveredal que circula por los caminos y así nos lo había anunciado Eutimia Coy el año anterior estando con ella en la Plaza de las Sepulturas.

Ya le digo que fue lo que pasó.

Pues Sí, la gente toda convencida, pero, pero yo le digo lo que pasó.

Todo el mundo, por ejemplo mire aquí tienen los carros y ya pasan por los caminos y ya van comprando todo el mundo.

Entons, ¿p'a qué vienen acá?

Esto era boniiiito, antes deeeee.... P'a todo, esto era lleno, pero antes deeee que todos llegaron y llevan las comidas por las calles, los caminos y tooodo. Entonces ya no,

- ¿Usted es de aquí?

-Yo soy de acá, de mi casa, me llamo Eutimia Coy.

- ¿Mucha familia Coy?

-Ya se va acabando, ... porque se van muriendo ya, ya queda muy poca familia Coy, pero ya, quedan Suárez al otro lado de la vereda. Ya eso allá Finos y Suárez y todos, si, allá ya es otra parte... si, ya allá quedan Suárez, ya quedan aquí también Fino's que son solo Fino...

Yo ya ahorita no cultivo... me tocó hace poco dejarle todo al hijo que trabaje.

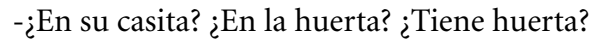

-No, no tengo huerta porque estoy enferma y no puedo hacer nada y no hay quien me ayude.

...es que no tengo quien ayude; y si, yo tenía mi huerta sembraba de cebolla, cilantro, nabos, turubos ( $\mathrm{sic}$ ), tallos,....papitas...de todo, la huertecita era chiquita pero... y ahora no porque estoy enferma, tengo hasta temblor en las piernas, de verdad estoy enfermaaaa... ${ }^{6}$

En este contexto, los mercaderes recorren carreteras terciarias y caminos veredales; apoyan y vinculan zonas y comunidades alejadas y facilitan a los campesinos aliviar las pesadas cargas de alimentos y productos que se transportan entre periferias y zonas urbanas. Sin embargo, las plazas de mercado aún siguen siendo lugares donde se expresan metáforas fundacionales de la cultura -estructura, roles, dramaturgia, montaje, fuerzas protagónicas y antagónicas, conflictos, etc.- parecerían campos de resistencia que las administraciones locales urgen adaptar a nuevas formas de encuentro como son las canchas de juego cons- 
truidas sobre sus cimientos, mientras que en virtud de los cambios económicos y sociales del país, el mercadeo y la movilidad se activan por los ingeniosos comerciantes locales y ocasionales capitalistas foráneos.

Es decir que, las redes de distribución participan de un fenómeno de DES-PLAZAMIENTO mediante el uso del transporte veredal repartidor, el distribuidor y comercializador de alimentos, entre pequeños productores y consumidores rurales; dinámicas que inciden también en los desplazamientos sociales y de la cultura.

Las reuniones y charlas con actores locales han sido grabadas por medio de audio, fotografía y video. Los documentos resultantes se convierten en huellas de memoria y a la vez son la imagen de sí mismas que se devuelve a las comunidades y sirven para impulsar una estrategia no solo de difusión sino de pensamiento centrado en la realización de exposiciones e intervenciones en diferentes lugares relacionados con el patrimonio, el arte, la cultura.

\section{Lo visual colaborativo}

Promover la curiosidad por ver, mirar y sentir nuestros entornos, referir el espacio del arte a la vida cotidiana, poner la sensibilidad a favor del conocimiento y potenciar la creación y el encuentro en virtud de la relación estética (Bourriaud, 2008, p. 106) y su incidencia en la vida comunitaria, anima las prácticas artísticas y colaborativas que establecen vínculos entre las maneras de ser y los modos de hacer (De Certeau, 1999, p. 80). Entre la fotografía, el audio y el video con nuestros paisajes sociales y territorios culturales se movilizó el deseo y el intercambio al interior del entorno social y con el entorno físico.

Para Bourriaud (2008, p. 13),

La posibilidad de un arte relacional -un arte que tomaría como horizonte teórico la esfera de las interacciones humanas y su contexto social, más que la afirmación de un espacio simbólico autónomo y privado- da cuenta de un cambio radical de los objetivos estéticos, culturales y políticos puestos en juego por el arte moderno.

Esta concepción, 'desterritorializa' el acto creativo del capital y expande los límites del arte que ahora escapa de instituciones y circuitos legitimados para instalarse en la experiencia. Por su parte, Michel de Certeau, centra su reflexión sobre el lugar de lo estético en la comprensión de las maneras de hacer cotidianas que marcan una diferencia entre la población consumidora de bienes culturales y los productores de esos bienes (De Certeau, 1999, p. LI) Situados en esta aproximación a la experiencia en el arte, dotado de aspectos tanto íntimos como comunes, dimos apertura a la creación de mundos posibles, de imaginarios que conciernen a la vida común y a la producción de múltiples perspectivas, tonos, texturas y cualidades.

Dada la singularidad, se legitiman convergencias, contra-dicciones y trans-formaciones en el transcurso y desarrollo del proceso. Considerando que el artista actúa en defensa de lo íntimo, desde aquellos lugares que pertenecen al territorio de lo público: la plaza de mercado, lo común; la huerta, lo doméstico; el salón comunal, lo comunitario, introduce 
al proceso colaborativo actuar en la cultura y en el colectivo marcando matices, aperturas de foco y profundidades de campo que emergen como capas de sentido en la imagen.

El arte, vinculado a la vida cotidiana atiende al llamado del sentir, compartir, vincular y más que juntar u homogeneizar, más que diluir una idea o una propuesta como una única solución, despliega la singularidad en cada quien que lee y se relaciona con sus acciones, textos, imágenes. Por ello decimos que el arte es aliado de la libertad para intercambiar palabras, bienes o regalos (Sen, 2000, p. 4), aunque no decimos con ello que el arte tiene 'una función' sino que, al referir al acto poético crea mundos, activa resistencias y aboga por la apertura de límites, fortaleciendo la acción (en el sentido de Arendt, 2009, p. 236) como aliada del deseo y la fuerza en un ejercicio de lo político (Rancière, 2006, p. 73).

Para Hanna Arendt (2009, p. 236), la acción es la posibilidad de recrear la vida en lo plural, de un nuevo comienzo en donde cada quien se da a conocer desde su singularidad: "el hecho de que el hombre sea capaz de acción significa que cabe esperarse de él lo inesperado, que es capaz de realizar lo que es infinitamente improbable".

Esta concepción se conecta con el concepto de política de Jacques Rancière, para quien los procesos de gobierno representan a la policía que define las formas de comportamiento y de relaciones. La política es la acción de los sujetos que interrumpen el curso de los actos de gobierno (Rancière, 2006, p. 73).

En este proyecto, la acción fortalecida por la imagen permite dar un salto de autoafirmación e instala una política centrada en el protagonista: el campesino. Es de esta manera que el arte se instala en cada fisura que abre la imaginación rompiendo esquemas y modelos pre-supuestos.

Actuar bajo el principio de los modos de hacer permite expandir una 'mirada fotográfica' que mediante la imagen situada, comparte con el observador una experiencia estética referida a un lugar, donde la fotografía, el video y el sonido, como medios, construyen una relación tiempo y espacio para ser habitada por la imaginación.

La noción de imagen situada surge como una analogía del concepto de conocimiento situado (Haraway, 1995, p. 327). El proceso de producción de la imagen, su resultado y exhibición son determinados por los cuerpos, los tiempos y los lugares en donde se han generado. No se trata de llegar a una pose para retratar, sino más bien, de generar el instante de surgimiento del gesto libre y cotidiano mediante el establecimiento de relaciones de colaboración y reciprocidad. De esta manera, las imágenes se insertan en la cinta de lo cotidiano y por esta razón, en la devolución a la comunidad se instalan como experiencias propias pertenecientes al paisaje y a la vida.

\section{Documentos}

La fotografía se manifiesta como un tejido narrativo que acompaña a la visualidad a desentrañar el carácter tácti $\Gamma^{\prime}$ de la imagen, de manera que, la imagen más allá de la contemplación, revela un entorno estructurado por los vínculos y cualidades de un territorio habitado. Cuando se afirma que el mundo está saturado de imágenes, habría que preguntarse por las características y temáticas de estos contenidos dominantes. El efecto táctil es un choque en el cual la percepción envuelve al cuerpo y al ser y los sitúa en relación con el propio territorio. 
Si se piensa en los medios masivos, éstos son orientados por las dinámicas y lógicas del entretenimiento y la información. Para Benjamin, la información nos aleja del mayor potencial de la comunicación: el intercambio de experiencias. En la medida en que los relatos de los medios audiovisuales sean más generales y concretos, se alejarán más de esa posibilidad de narrar y se quedarán en el ámbito superficial de informar.

La información tiene interés tan sólo en el breve instante en el que es nueva. Sólo está viva durante ese instante, y a él se entrega por completo sin tener ningún tiempo que perder. Pero la narración jamás se entrega, sino que, al contrario, concentra sus fuerzas, y, aún mucho después, sigue siendo capaz de desplegarse (Benjamin, 2009, p. 48).

El objetivo de estos actos fotográficos, $\mathrm{NO}$ ha sido informar ni exaltar las virtudes esteticistas, ni las texturas rítmicas de un artesano tejedor, por el contrario, plantean compartir una imagen que capta las singularidades del territorio habitado por el cuerpo-rostro, desplazando un lenguaje que apenas trace los bordes de la imagen.

\section{Escritura}

Exponer o compartir la imagen es devolver un texto que ha sido escrito 'en colaboración'; entendemos que ésta es la condición de posibilidad para que un sonido, una fotografía, una imagen en movimiento, desarrollen su potencia, resuenen con el interés de situar una imagen de sí.

Instalar un diálogo entre el sujeto protagonista y el sujeto que "registra" es el punto 0 a partir del cual se implica no solo la producción de la imagen, sino también la lectura como un ejercicio colectivo; colectivamente nos referimos al mismo texto/imagen, aunque cada experiencia sea individual; la lectura, que paradójicamente se dispone al colectivo, se hace individualmente como un acto de afirmación de quien lee; cada quien lee, interpreta y estructura sus propios significados, y a la vez que estos significados pasan por un registro colectivo, nos permiten interactuar, reconocer-nos, identificar-nos y situar-nos. La imagen-texto cuya finalidad no es informar sobre un asunto específico, convoca a cada uno de los actores vinculados con el territorio/paisaje a que desentrañen sus propias narrativas y que seguramente encuentren aspectos resonantes entre ellos mismos y con otros 'espectadores'... Es así como, las múltiples capas de sentido que se desentrañan al leer la imagen, tienden a vincular más que a cumplir con un objetivo; no es necesario un narrador externo que sirva de mediador entre la realidad y lo que la imagen capta.

¿Cómo disponer y desplegar el paisaje para que deje de ser una 'figura' que des-cribe con líneas el horizonte lejano y mudo a los ojos?

Un hombre, vestido con chaqueta, habla de su historia: ha trabajado en el campo, cultivando desde hace cincuenta años; él tiene sesenta. Va al volante de un carro; el carro recorre una carretera accidentada. Por la ventanilla al lado del 
conductor se puede ver la vegetación que está en el borde del camino. El verde y la luz del sol contrastan con la oscuridad interior del vehículo.

Hay un cambio de plano; ahora el mismo hombre, con sombrero, está parado frente a un campo amplio; al fondo se ve el cielo azul, con algunas nubes. Hay pequeñas montañas y el color del paisaje tiene varios matices de verde. Es una hondonada que parece muy fértil; en la mitad, un ojo de agua. De nuevo un cambio de plano.

Un carro amarillo, tipo "campero" está estacionado bajo un techo que se sostiene por columnas de metal. Tras al carro, una mujer, vestida de bluyín y saco negro, con botas de tacón y un sombrero, está parada; al lado, dos perros. En una banca, al lado del carro, hay una bolsa plástica con algo dentro. La puerta trasera del carro cubre casi todo el cuerpo del mismo hombre que entrega algo a la mujer ${ }^{8}$.

En esta descripción se presentan imágenes situadas. Es una representación cotidiana de actividades que les son cercanas a los protagonistas. Se podría afirmar que es una imagen de lo común, de la comunidad. Aunque no lo conozcan personalmente, los espectadores de esta región saben quién es este hombre: un carranguero, un campesino, un hombre de la tierra.

Lo que vemos en los videos realizados, por ejemplo, es la presentación del entorno en el cual han ocurrido los encuentros con campesinos -hortelanos y comerciantes- donde la imagen muestra a los personajes y dibuja las geometrías de sus entornos. Al ser expuesta en lugares públicos veredales y municipales, implica a los asistentes. Se integra como un ingrediente del relato común de los habitantes.

\section{Imagen de sí}

Los recorridos entre plazas, caminos y huertas nos han permitido, por medio de aparatos de registro, realizar una documentación de la experiencia.

La huella de esta experiencia se refleja ahora en una 'colección' compuesta de piezas fotográficas, de video y de audio: una colección en donde se puede 'mirar' el resultado de lo que ha ocurrido en el camino, en la ruta. Este reflejo-huella no es la huella del tiempo sino de la experiencia, corresponde a la aparición de una imagen constituida por contigüidades, por semejanzas y posiblemente vinculaciones afectivas y evocación de 'un recuerdo': es el síntoma que irrumpe en la colección y la estalla en múltiples sentidos.

De manera que estos documentos coleccionables y expositivos son más que referencias descriptibles de un paisaje; son mucho más que retratos de la realidad y de sus actores; son "la aparición de un síntoma que irrumpe y resiste a la observación banal" dice DidiHuberman (2011, p. 63). Quien mira la imagen "compone duraciones múltiples, tiempos heterogéneos y memorias entrelazadas”, es decir, que nuestro 'espectador' (que pudo haber sido también uno de los protagonistas) situado ante el abismo de su propio paisaje, lee un relato propio. Lo comparte.

Nuestra experiencia en la acción consistió en exponer las imágenes de manera que las fotos se pudieran manipular, tocar, comentar, circular... y estuvieron contenidas en "cajas 
de mercado", señalando que su origen se vincula con la relación huerta-mercado, producción-relato, vida cotidiana-intercambio. Resalta una paradoja de la que emerge la potencia radicante: la distancia del ojo que ve la imagen, es cercanía al mismo tiempo. Las fotos salen de sus cajas y circulan en las manos de quienes miran, la circulación genera un sentido de communitas, y la mirada, que es una experiencia singular, se vuelve colectiva.

Según Turner (1988, p. 103)

El sentido de communitas deriva de un estado o fase liminal, de la sociedad en comunidad, la cual se separa por momentos, como en los rituales, de la sociedad estructurada con roles diferenciados para cada persona, definidos por normas y autoridades. La experiencia del común, lleva a breves momentos de salida de la estructura social, luego de los cuales, la estructura se refunda, pero sobrevive la experiencia de la desestructuración en las huellas; en este caso, sobrevive en las imágenes, es decir, se activan las múltiples capas de sentido que tiene la imagen.

Ahora, la cercanía con la imagen, el poderla compartir, hacerla pasar de una persona a otra, permite que haya un re-conocimiento communitas. Se activan pensamientos y sensaciones que resuenan en grupo sobre el entorno que se habita. Los cuerpos no están en el paisaje; el paisaje llega desde la imagen, a visitar los cuerpos.

Como expresamos anteriormente, la relación con la imagen trasciende lo visual y se vuelve táctil. La imagen incluye al cuerpo y activa el espacio. No son imágenes dispuestas para sobre-cogerse con ellas sino para que entren en el espacio de quien mira. Es la misma lógica de la mirada táctil a la que Benjamin (1989, p. 90) refiere para el cine. La foto permite pensar porque es móvil, y al ser móvil no entra en el registro de la mercancía sino en el de los bienes comunes.

Para el espectador la distancia con la imagen no diferencia a quien observa de la cosa observada. La imagen implica a las personas. Esto se materializa, según Didi-Huberman (2008, p. 66), en lo que Benjamin, admira de la imagen en la Pequeña historia de la fotografía: la posibilidad de "ofrecer una experiencia y una enseñanza"; no en el sentido didáctico sino en el del reconocimiento del propio entorno en la imagen. No es una identificación, es la capacidad de "ver sintiéndose mirado"; de "perdurar, permanecer, habitar un cierto tiempo en esa mirada-ahí, en esta implicación".

El sujeto no ve su yo en la imagen; más bien puede decir quien está en la imagen podría ser yo; la implicación mantiene la tensión sin explicar. La imagen es una presencia implicante porque quienes la miran comparten sentidos y vínculos.

La colección de imágenes (foto, video y sonido) se ha convertido en un archivo vivo: una serie de piezas que dibujan el mapa de la región desde los sentidos. El archivo cobra vida cuando se exhibe y circula; cuando irrumpe en la cotidianidad de un espacio público y se hace común.

Una característica de esta colección es la errancia, pues se ha construido en el camino radicante; el carro, la carretera y el recorrido permitieron el encuentro para su producción. Ahora, el sentido de la mirada en el paisaje es relacional y se consolida con la circulación, permite que el paisaje no se imponga como forma sino como experiencia; esta imagen es sentido. 
Los contenidos plasmados en los documentos de la colección responden a una lógica de producción que ha privilegiado el encuentro desde lo cotidiano. Por esto, son imágenes que tienen la fuerza de irrumpir en el espacio público y "hacer pensar".

Según Rancière (2010, p. 20), "el espectador tiene autonomía para interiorizar las imágenes y no son los autores quienes dictan un modelo de interiorización o elaboración de la imagen". En la creación de imágenes se dicen cosas que no estaban contempladas por el productor; los productos de este proceso, son ambiguos. El arte resiste la mirada. Nuestras errancias producen experiencias.

La potencia de las imágenes, de los documentos, radica en el hecho de que se oponen al flujo dominante de imágenes e informaciones que no dejan ver la cotidianidad; que minan el sentido de lo común porque se refieren a un orden, a una puesta en escena impuesta.

Los espacios: la plaza, la carretera, la huerta, son representados de manera doble: están en el recuerdo, están en la imagen. Esto genera una dialéctica de la mirada (Didi-Huberman, 2008 , p. 63) y es la base de la implicación de la comunidad; le da relevancia al proceso de producción y a la exposición del resultado.

\section{Performatividad de lo visual}

La experiencia relacional debería en consecuencia tratar de articular estas esferas múltiples a base de posibilitar la intervención continua en ellas, pero no en un ámbito físico, como si dejar un regalo, establecer una instalación o hacer una performance fuese el hecho constitutivo de la intervención ${ }^{9}$.

La intervención con imágenes expone al poblador, al asistente, a una situación de descubrimiento del vínculo, a lo que de cada 'objeto' da sentido -pasado y futuro-, lo que a la vez se constituye en nuestro 'vínculo con la tierra'. De ahí, consideramos que la experiencia radicante se instaló en un diálogo performativo, actuando mediante los encuentros en una esfera de la acción. En la acción expositiva, tres lugares, tres espacios de encuentro, invitamos a poner en un primer plano de la interacción la sensibilidad del observador respecto a la imagen; lo registrado - documentado, a manera de gestos impresos fué vinculante entre los que comparten la tierra y constituyen el paisaje.

Para Schechner (2000, p. 123), la performatividad en la cultura consiste en un corte en la "cinta de conducta habitual" un corte que restaura una conducta, una relación, re-activa vínculos; desdibuja las fronteras entre las personas; entre el cuerpo y la mente, entre la vida y el arte.

De esta esfera del sentido, la experiencia visual hizo alianza con el cuerpo del que mira de manera que el habla, al estar instalada y naturalizada en la gestualidad, se relegó a un segundo plano; nuestra insistencia en actuar en una esfera de la estética relacional, logró a activación de circuitos sensibles -que pertenecen según Rancière (2006, p. 73) a la política. Es esta experiencia relacional la que puede borrar fronteras comunicativas y pasa de un diálogo textual al 'diálogo' performativo para buscar lo que hay más allá del discurso tanto para los artistas como para los participantes de las comunidades; como diría Jordi Claramonte (2008): la base para el agenciamiento de la esfera estética es un espacio en 
que la imagen transita de lo doméstico a lo público, de lo íntimo de la vida cotidiana a lo compartido por las redes de intercambio, o, en últimas nos preguntamos si de la plaza de mercado a la venta ambulante.

Ante una imagen -tan reciente, tan contemporánea como sea-, el pasado no cesa nunca de re-configurarse, dado que esta imagen solo deviene pensable en una construcción de la memoria, cuando no de la obsesión. En fin, en una imagen tenemos humildemente que reconocer lo siguiente: que probablemente ella no sobrevivirá, que ante ella somos el elemento frágil, el elemento de paso, y que ante nosotros ella es el elemento del futuro, el elemento de la duración. La imagen a menudo tiene más memoria y más porvenir que el ser que la mira (Didi-Hubermann, 2011, p. 32).

\section{Notas}

1. La mesa: espacio escultórico de encuentro intercambio, reciprocidad y circulación entre hortelanos rurales y hortelanos urbanos. Grupo Raíz Cuadrada. http://www.trixiallina. com/la-mesa

2. Convocatoria Ministerio de Cultura de Colombia - 2016.

3. Hablar de producir una Imagen de sí es un intento por abordar el cuerpo/gesto en su entorno y más allá de un 'yo me reconozco técnicamente en la foto' ingresar a un 'me reconozco en mis relaciones'; buscamos que no sea el YO el que se pone en consideración dado que es el grupo o "todos" los que hacen parte de la imagen. Este es un primer intento por el re-conocimiento de pertenencia al paisaje dado que ha sido construido por ellos, por sus 'ancestros', sus familiares; porque les pertenece y lo conocen. Es por ello que referimos a las tres esferas de la sensibilidad al decir del gusto, el conocimiento y la expresividad.

4. Departamento de Boyacá, Colombia.

5. Este mercado está reseñado como parte del patrimonio cultural en el Centro de Arqueología, Historia y Patrimonio - Herencia Mía http://herenciamia.org/ricaurte/items/show/85.

6. Conversación con Eutimia Coy, en Plaza de las Sepulturas, Vereda Ermitaño, Sutamarchán. www.trixiallina.com/radicante: Gestualidad hortelana.

7. Según Benjamin (1989: 90) el carácter táctil de la percepción no obedece a la contemplación del objeto artístico propia del régimen visual; lo táctil corresponde al acostumbramiento del cuerpo en el lugar que habita.

8. Descripción de uno de los videos realizados.

9. Jordi claramonte, arte colaborativo, política de la experiencia -http://jordiclaramonte. blogspot.com.co/2008/05/arte-colaborativo-politica-de-la.html

\section{Referencias}

Agamben, G. (2016). Gusto. Buenos Aires: Adriana Hidalgo Editora.

Agamben, G. (2007). La potencia del pensamiento. Buenos Aires: Adriana Hidalgo Editora. 
Arendt, H. (2009). La condición humana. Buenos Aires: Paidós.

Benjamin, W. (1989). La obra de arte en la época de su reproductibilidad técnica. En: Discursos Interrumpidos I, Buenos Aires: Taurus.

Benjamin, W. (2009). El narrador. En Obras, II, 2, pp. 41-67, Madrid: Abada.

Benjamin, W. (2011). Breve historia de la fotografía. Madrid: Casimiro libros.

Bourriaud, N. (2008). Estética relacional. Buenos Aires: Adriana Hidalgo Editora.

Conti, R. (2014). Acerca del componente estético en la reflexividad marcuseana. VIII Jornadas de Sociología de la UNLP, 3 al 5 de diciembre de 2014, Ensenada, Argentina. En Memoria Académica. Disponible en: http://www.memoria.fahce.unlp.edu.ar/trab eventos/ev.4520/ ev.4520.pdf [Consultado 28/02/2018].

De Certeau, M. (1999). La invención de lo cotidiano. México: Universidad Iberoamericana.

Didi-Huberman, G. (2008) La imagen quema. En: La Puerta FBA; no. 3. Universidad Nacional de La Plata.

Didi-Huberman, G. (2011). Ante el tiempo, historia del arte y anacronía de las imágenes. Buenos Aires: Adriana Hidalgo Editora.

Haraway, D. (1995). Ciencia, cyborgs y mujeres: la reinvención de la naturaleza. Madrid: Ediciones Cátedra.

Claramonte, J. Arte colaborativo, política de la experiencia. http://jordiclaramonte.blogspot. com.co/2008/05/arte-colaborativo-politica-de-la.html [consultado 30/11/17]

Rancière, J. (2006). Política, policía, democracia. Santiago: LOM Ediciones.

Rancière, J. (2010). El espectador emancipado. Castellón: Ellago Ediciones.

Schechner, R. (2000). Performance. Teoría y prácticas interculturales. Buenos Aires: Libros de Rojas/UBA.

Sen, A. (2000). Desarrollo y libertad. Buenos Aires: Planeta.

Turner, V. (1988). El Proceso Ritual. Madrid: Altea, Taurus, Alfaguara.

\begin{abstract}
This paper will tell about the Mesa radicante project that was an experience within the process of Proyecto Huerta that stimulates the emergence of narratives about the territory through different strategies looking to make visible through images the situation, the place and the actions, and establish a link between the rural and the urban.
\end{abstract}

Keywords: process - strategies - narratives - image - rural -urban.

Resumo: Será relatado sobre o projeto Mesa Radical que foi uma experiência enquadrada no processo do projeto Huerta que através de várias estratégias estimula a surgimento de narrativas territoriais buscando tornar a situação, o lugar e as ações visíveis na imagem, e estabelecer um vínculo entre o rural e o urbano.

Palavras chave: Processo - estratégias - narrativas - imagem - rural - urbana

[Las traducciones de los abstracts fueron supervisadas por el autor de cada artículo] 